\title{
Psychotherapy of a Preschool Cancer Survivor: Promoting Mastery and Understanding
}

\section{Douglas Davies, M.S.W., Ph.D. ${ }^{1}$}

$A B S T R A C T$ : The prolonged and invasive treatment common to cancer therapy protocols may lead to precocious defenses which impede the future development of preschool-aged cancer survivors. Focal play therapy offers the young cancer survivor a chance to understand and master the cancer experience. At present there are no accounts in the literature of the psychotherapy of young cancer survivors. This paper presents a detailed account of the therapy of a preschooler who survived a brain tumor, emphasizing the child's perspective on the cancer experience and an intervention approach which stresses mastery of developmental impasses, rather than psychopathology.

\section{Introduction}

As medical treatment for childhood cancer has improved, larger numbers of children are surviving cancers that previously were almost always fatal. Paradoxically, successful medical treatment may produce negative developmental side effects. The prolonged and invasive treatment common to cancer therapy protocols may constitute an interference to subsequent development in young cancer survivors (Rowland, 1989; Van Dongen-Melman and Sanders-Woudstra, 1986).

While there have been numerous studies of children's reactions and adjustment to hospitalization, as well as several studies of long term sequelae of childhood cancer, there is little in the literature about how young survivors function during the year or two after remission, when developmental effects might be more easily assessed. Further, it is difficult to sort out the effects of age and developmental level in

Dr. Davies is a Lecturer and Social Work Specialist, Infancy and Early Childhood Clinic, Department of Psychiatry, and an Adjunct Assistant Professor, School of Social Work, The University of Michigan, Ann Arbor, MI. Address communications to the author at 1549 Broadway, Ann Arbor, MI 48105. 
the existing empirical literature, because most studies combine subjects whose age at diagnosis ranges from infancy through adolescence. The requirements of sufficient sample size have often created heterogeneous samples which obscure differential outcomes based on age and developmental level (Siegel, 1990).

In part because of the above limitations, studies of the long term effects of cancer diagnosed in early childhood present a mixed picture. Koocher, et al. (1980) found that children diagnosed with cancer when under age 5 were less likely to develop adjustment problems than survivors who were school aged at diagnosis. However, they were careful to qualify this finding by stating that two of the most common cancers with onset in early childhood, Wilm's tumor and neuroblastoma, are more easily treated and have a good prognosis. Other studies have found poorer adjustment in various areas of development among cancer survivors compared with controls, yet the survivors' scores on normed instruments do not always reach criteria for pathological adjustment (Greenberg, et al., 1989; Deasy-Spinetta, 1981). At the same time a number of researchers, in reporting such findings, have expressed surprise that such a stressful experience as cancer treatment does not produce long term effects (Greenberg, et al., 1989; Fritz, et al, 1988). Fritz, et al. (1988) state "Qualitative changes that do take place [in response to the illness] are more often subtle than gross, and they may elude standard quantitative instruments." Commonly-used instruments, such as the Childhood Depression Scale or the Child Behavior Checklist are designed to reveal functioning that suggests the presence or absence of psychopathology. They do not assess interferences to development. Nor, because they aim to elicit quantifiable data, do their designs permit the child to represent his or her experience in a way that would preserve its affective and cognitive complexity.

Nevertheless, one recent well-designed quantitative study suggests that children diagnosed during the preschool years may be particularly vulnerable to developmental interference as a result of cancer treatment. Mulhern, et al. used the Child Behavior Checklist to assess 183 long term survivors whose mean age at diagnosis was 2.7 and found a 3-4 fold higher incidence of abnormalities in behavior and social competence compared to instrument norms. (Mulhern, et al., 1989) This is consistent with the general findings of developmental research suggesting that the younger the child, the fewer internal resources he or she has for coping with stress. (Maccoby, 1983; Kagan, 1983) The preschool child-because of his or her egocentric perspective, limited internalized coping mechanisms and limited abili- 
ties in understanding and communicating about experience-may especially benefit from interventions which help promote mastery of the cancer experience.

However, it is important to note that a number of protective factors may help preserve the normal developmental trajectory of preschool cancer survivors. Foremost, the attachment relationship with parents remains an adaptive mechanism for coping with distress (Cicchetti, et al., 1990; Barton and Zeanah, 1990). Parental availability and transactional patterns based on secure attachment and parental responsiveness can be drawn upon to help the child weather pain and anxiety associated with medical procedures and hospitalization. Other protective factors include the child's history of success in mastering earlier developmental tasks, family cohesion and stability, and outside supports for parents (Rutter, 1983; Barton and Zeanah, 1990).

The thrust of most intervention programs has been to augment these protective factors through family interventions and self-help support groups, such as the Candlelighters (Chesler and Barbarin, 1987). Although such interventions have demonstrated value, they implicitly focus attention toward family processes and away from the subjective experience of the child who has undergone cancer treatment. There is also an extensive clinical literature on in-hospital interventions aimed to help children cope with pain and with invasive or potentially frightening medical procedures (Jay, 1988; Rowland, 1989; Adams-Greenly, 1989). But surprisingly little attention is given in the literature to individual interventions that address the developmental aftermath of cancer treatment. Mulhern, et al. (1989) recommend routine annual screening for psychological adjustment problems after medical treatment has been completed; others make general suggestions that play therapy may be helpful (Rowland, 1989). The few studies that deal with psychotherapy of cancer survivors focus on interventions to help school age children and adolescents re-enter school and peer relationships (Kagen-Goodheart, 1977; Lansky, et al., 1983). No doubt many clinicians have been working with young survivors to intervene with problems of adjustment and development; however, there are no accounts of the psychotherapy of preschool childhood cancer survivors available. This may owe to the contemporary view that case studies are "unscientific." But case studies can help fill the gap between empirical studies and clinical practice, especially when a case embodies salient issues identified in schematic form in empirical research, or presents a useful intervention approach (Wells, 1987).

This paper is an account of the psychotherapy of a preschooler who 
survived a brain tumor. Its primary aims are: 1) to present a young child's "story" of having brain cancer from the perspective of her internal life, as represented in her play; 2) to present an intervention approach which focuses on the child's reactions to cancer treatment, and emphasizes the mastery of developmental impasses that are the sequelae of cancer treatment, rather than psychopathology. The presentation begins with a brief review of issues in the interaction between preschool development and cancer treatment, in order to provide a context for the case study.

\section{Developmental Perspective}

Cancer treatment typically involves the onslaught of a number of stressors, including hospitalization, anxiety about dying, pain from spinal taps, bone marrow aspirations and other procedures, nausea and weakness as side-effects of chemotherapy, bodily changes such as hair loss, loss of familiar routines, disruption of friendships and in some cases separation from parents (Van Dongen-Melman and Sanders-Woudstra, 1986). Rutter noted that the capacity of preschool children to cope with future stresses was altered by the stress of multiple hospitalizations. Coping styles developed in response to the stress experienced during hospitalizations tended to persist even if they were not adaptive from the perspective of the tasks of future development (Rutter, 1983; Trad and Greenblatt, 1990). Many preschoolers seem to develop a precocious maturity, becoming unexpectedly compliant with treatment; however, this precocity may later show up as inhibitions and behavioral rigidities which interfere with development (Katz, 1980; Rowland, 1989). Compared to the latency age child, the preschooler's internal mechanisms for coping with stress are not yet well developed. The more sophisticated defenses characteristic of the latency child-repression, rationalization, denial in fantasy-are not yet in place. Lacking adequate coping strategies, the preschooler is more likely to become overwhelmed during stressful procedures and may either shut down emotionally or lose control and dissolve into tantrums. (Jay, 1988) A study of child cancer patients undergoing bone marrow aspiration found that children under 7 experienced distress levels 5 to 10 times higher than those of children over 7 (Jay, et al., 1983). Gauvain-Piquard, et al. (1987) noted that preschoolers have depressive reactions to painful medical treatment that correlate with the intensity of the pain. Given the evidence 
of the preschooler's difficulties in coping and the negative impact on future development of adaptive coping mechanisms, it is worth asking whether cancer treatment with multiple hospitalizations might have a more profound effect on the development of preschool children than on school age children or adolescents.

Prolonged invasive medical treatment is likely to interfere with a number of developmental tasks of early childhood, including the development of an autonomous self, beginning peer relationships, elaboration of play and fantasy, and control of one's body in terms of regulation of body functions, physical activity and mobility (Rowland, 1989; Brunquell and Hall, 1982). At a time when these developmental issues are in ascendancy and therefore subject to disturbance, cancer treatment and hospitalization cause the preschooler to experience a loss of autonomy and self-control, increased dependency, isolation from peers, restrictions on freedom to play, restrictions on physical activity and mobility, and physical vulnerability because of invasive procedures and the side-effects of chemotherapy (Van Dongen-Melman and Sanders-Woudstra, 1986; Chang, 1990).

During the preschool period the ability to play imaginatively is a major adaptive mechanism for the mastery of stress, as well as the primary pathway for exploration which facilitates learning and socioemotional development. Play supports the development of autonomy and initiative (Piaget, 1962). Cancer treatment disrupts the child's ability to play actively and strenuously (Lansky, et al., 1985). A study of fantasy in children and adolescents with cancer noted that the ill children, compared to controls, tended either to refuse to fantasize or to impose rigid controls on their fantasies, "so that the frightening themes found in healthy children were avoided" (Zeltzer and LeBaron, 1986). In the well children, fearful imagery could be tolerated because it was countered by fantasies of control and mastery. It appears that the fearful fantasies typical of early childhood were all too real for the children with cancer and were associated with failures at mastery; consequently they sought to inhibit them. Deasy-Spinetta (1981) also noted that upon returning to school, children with cancer tended to "hold back;" they were inhibited in their ability to express positive and negative feelings and tended to take a passive role in peer interactions.

The likelihood of developmental interference is increased by the preschooler's cognitive characteristics, which include egocentrism and prelogical, magical thinking, which does not distinguish between intention and result or between cause and effect, especially when 
stressors are operating. For example, the preschooler tends to develop distorted notions about the causes of his or her illness, including mistaken associations between the onset of the illness and coincidental external events, and is likely to regard invasive and painful medical procedures either as sadistic abuse or as punishment for misdeeds (Bibace and Walsh, 1980; Jay, 1988). Further, the preschooler has limited ability to understand abstract explanations of medical issues that he or she may overhear in the hospital, and is prone to impose idiosyncratic constructions on them (Bergmann and Freud, 1965).

\section{Case Presentation}

The case of Katy is an interesting example of a developmental arrest caused by a preschooler's reactions to a serious illness following an early history of excellent development in the context of a stable and loving family. Although the cancer treatment was at times frankly traumatic and at other times quite stressful for this 3-4 year old girl, her excellent endowment, previous developmental progress and remarkably supportive parents combined to protect her from more severe effects of the treatment. Nevertheless, she did show evidence, at age $4 \frac{1}{2}$, of developmental arrests in the social and affective areas. Therefore, the case is an instructive example, of how a young child, who was buffered by an array of protective factors, coped with a severe illness.

\section{Assessment}

Katy is from a middle class family. Both parents work in professional fields. She has a brother who is two years younger. Katy's early development was excellent. Up to the onset of her symptoms at age 3 she was a vivacious, outgoing child, who played vigorously and had a good sense of humor. Near her third birthday, her parents noticed that Katy seemed to become moody and that she "stopped playing." Over the next three months she became more and more somber and less and less active. She complained of feeling weak and began to have headaches. But her pediatrician could not find any evidence of illness. When she refused to get out of bed because her head hurt, her parents took her to the emergency room. She was admitted and within a few days was diagnosed as having a malignant brain tumor (EpendymomaGrade 3) at the back of her head. Three days later the tumor was removed in an eight hour surgery. She was in tremendous pain for ten days following removal of the tumor. Over the next seven weeks of hospitalization she had several minor surgeries, including the placement of a shunt, two repairs of the incision and the placement of a broviac catheter in her chest wall. Altogether she underwent general anesthesia six times. One repair of the incision was done without anesthesia, and seems to have been traumatic-Katy became hysterical and had to be held down and the doctor yelled at her to stop crying as he restitched the wound. She also received cranial radiation, which caused her to lose the hair on the back of her head. Over the next 15 months, 
Katy was hospitalized 10 times for 2 day periods for chemotherapy. As she realized that the chemotherapy made her feel terribly ill, she began to resist and had to be coaxed by her parents; twice she became very upset when an exasperated nurse told her she'd make her parents leave the hospital if she didn't cooperate. (In reality, one of her parents was with her at all times during her hospitalizations). Most of the time, however, she seemed to submit passively. She told her parents that she thought the chemotherapy might make her die. There were also many other invasive procedures, ranging from extremely painful spinal taps to needle pokes for i.v.s and blood draws. Her parents reported that Katy was forced in the hospital to do things she didn't want to do-to have intravenous needles changed, to be awakened in the middle of the night to go to the bathroom, and, in general, having to adapt to the hospital routines. Her parents and the medical staff, however, had explained what was happening to her, and her parents had been remarkably supportive and consistent with her, in spite of the tremendous stress her illness imposed on them. Katy, for her part, had been cooperative or stoic in response to all but the most surprising or painful procedures. By the standard of overt distress, which is commonly seen in the literature as a measure of coping (Blount, et al., 1991), Katy seemed to have tolerated her medical experiences well. She had used an array of coping mechanisms, including using the support of her parents and the medical staff, complying with medical procedures, and affective strategies such as denial and blocking of affects. At the time of my evaluation Katy was able to talk calmly about the medical procedures. She knew what had happened to her. She said she didn't like being hurt, but that she had tried to help the doctors. For example, she said, "Some kids have to be made unconscious when they get a CAT Scan because they might wiggle too much. But I didn't have to be made unconscious. I wanted to help them, so I just lied real still."

Another consequence of her illness was that she had to be kept away from other children when she was out of the hospital. The chemotherapy seriously compromised her immune system, so that an ordinarily mild illness like measles would be life threatening to Katy.

I began seeing Katy when she was 4 years 8 months. At that point her cancer treatment was completed and medically she was doing well. Her parents were aware that her cancer could recur and also that she would be at risk for developing leukemia later on. They referred her to me because she had become such a serious, quiet, inhibited child, quite different from the vivacious 2 year old they remembered. They were concerned that she had reactions to her hospitalizations and fears of death that she could not talk about. She was extremely cautious physically and no longer threw herself into play. She refused to do "risky" play like swinging, jumping or climbing. Katy told me she thought she'd gotten cancer because she fell off the jungle gym when she was 3 . She was enrolled in part-time daycare, but was standoffish with other children and played mostly by herself, probably because she had missed out on learning to play with other children over the previous year and a half, and also because she was still afraid of catching a disease from another child. She also seemed arrested in her ability to play. At home, at day care and in the early treatment sessions, her play had a constrained, tentative and obsessional quality and lacked the rich fantasy themes typical 
of a 4 year old. Although Katy did not show symptoms of psychopathology, there were nevertheless many indicators that her experience with cancer treatment was interfering with her development. My impression on meeting Katy, however, was that she had a full range of affect and fantasy available to herself, but that she kept them under wraps. I saw her as a high-functioning, ego intact child who, underneath her inhibitions and affective constriction, might be imaginative and articulate. I felt she showed good potential to make use of expressive psychotherapy.

The treatment goals were: 1) To help her recover the ability to play, in order to open up for her an age appropriate pathway for developmental progress and the mastery of stress. 2) To help her gain some mastery over the traumatic aspects of cancer treatment by playing out in an active way those experiences she had previously had to submit to passively. An essential part of this goal would be to give Katy a chance to present a range of affectsespecially anger and negativism - which she had suppressed during her medical treatment. 3) To help her differentiate her experience with cancer from her present experience. This would involve helping her see cancer treatment as a past experience, not a lens for viewing the present. These treatment goals were consistent with the recommendations of Susman, et al. (1980), who suggest that interventions with child cancer survivors take a non-pathologizing perspective which focuses on how the experience of cancer and its treatment impacts the tasks of a given stage of development. It was not assumed that Katy had a psychiatric disturbance, although her parents' description of her as quieter, more inhibited and self-contained, less active physically and less social, raised the possibility that her reactions to cancer treatment had interfered significantly with the pre-cancer trajectory of her development.

The therapeutic approach in this case was a focal psychotherapy to help a child master a potential developmental interference (Chethik, 1989). The treatment modality was individual play therapy and parent guidance. (The parent work will not be described, because it was minimal. The case is atypical in this respect. Ordinarily, parents also need a chance to work through the traumatic impact of their child's life-threatening illness. Katy's parents had done a remarkable job in helping Katy cope with her illness and in coping with it themselves. They had already made extensive use of outside supports, including a family intervention during Katy's illness). The play of preschoolers in the therapeutic situation is best seen as the child's representation of significant aspects of her experience and as a commentary on what her experience has meant to her. Starting from this assumption, it becomes the job of the therapist to locate the meaning of the play and then to provide interpretive commentary which helps the child's development proceed. At the outset, the therapist makes statements about the problem for which the child has been referred. I told Katy, "Your mom and dad wanted you to see me because they think you might have some worries and scary feelings about cancer and the hospital. My job is to help girls with their worries and your mom and dad thought I might be able to help you." If this problem statement is salient for the child, play representing the child's experience of the problem begins to emerge. For Katy, this took the form of her laying out 20 or so rectangular blocks and then placing small dolls lying down on each of them. I 
watched her and said, "This is too big to be a family; there are so many beds, I wonder if it's a hospital." Katy looked me in the eye and said "Yes." Through this process the play becomes focused, organized and meaningful. The child preconsciously understands that the therapist sees play as a representation of experience and begins to use it to express what has been difficult for her. In order to help focus the treatment I had a toy doctor's kit and some medical paraphernalia-surgeon's mask and cap, i.v. tubing, tape, etc.-available for Katy's use. I never directed her to play with these materials, but pointed out that she could use them to show me her worries, just as she could use the more standard child therapy toys.

\section{Treatment}

Katy's early play was inhibited and constrained. She chose to draw and play board games, speaking little and avoiding developing any fantasies in her play. I suggested play doh and as she worked with it small breakthroughs of affect began to occur. For example, she began to pound on it with her fist. When a piece dropped on the floor and Katy looked displeased, I amplified her facial affect by saying, "That stupid play doh! It fell on the floor!" Katy was pleased and repeatedly dropped the play doh, while I continued to express irritation. My aim was to demonstrate to Katy that negative affects could be safely expressed within the therapeutic situation.

The first significant play commentary Katy made on her hospital experience appeared in the third session. In the course of playing catch, Katy began hitting me on the head repeatedly with a foam ball. Given that Katy had had many hurtful things done to her head, I did not think this was random or merely diffusely aggressive behavior. I told her that of course it didn't hurt to be hit with the soft foam ball but that I would pretend to be hurt. I complained a lot about being hurt and she continued to hit me with the ball with a grim expression on her face. I also pretended to be mad, which she thought very funny. When she took up this play in the next session, I focused it around her medical treatment. I told her I would pretend to be a kid at the doctor's, who was getting hurt by what the doctor was doing. As she hit me with the ball, I said, "Doctor, that hurts. I don't like you to hurt me. I'm getting mad at you for hurting me." After a bit I stepped out of the play and said, "I'm showing how kids get very angry when the doctor hurts them. At this point, Katy got a girl doll, took off its clothes and began taping an i.v. tube to its chest. I spoke for the doll and asked if what the doctor was doing would hurt. Katy, as the doctor, gave a small, enigmatic smile and mumbled incomprehensibly. (This, it appeared, was her representation of the doctorsomeone who did hurtful things, all the while smiling and mumbling, but not being responsive to her feelings or questions).

Following this direct representation of medical procedures, Katy's play became more symbolic but still affectively salient. She developed a game of throwing markers on the floor and telling me "Pick 'em up!" This was repeated many times. I asked her how I was supposed to feel about having to pick the markers up all the time and she said, "You don't like it." I echoed this feeling each time she threw them on the floor. I commented that she was helping me understand how it felt to be forced to do something you don't want 
to do. I said her mom had told me she'd been forced to do a lot of things when she was in the hospital. Over the next few sessions, she elaborated the game. We would both pretend to go to sleep in my chairs. While I remained asleep, she would get up and throw markers and crayons all over the floor. Then she would turn over the play chairs with a big thump, which would be my signal to wake up, and pick everything up. Within the play, I said, "I hate to be waked up. I don't like to be forced to pick all this stuff up." Katy said, "You have to." I commented that a kid in the hospital wouldn't like it when the nurse woke her up and forced her to have a shot or made her get up and go to the bathroom.

This hospital play scenario was fully elaborated in a session 2 months into the treatment. As usual, Katy threw markers on the floor and turned the chairs over. While I was sleepily picking things up, I complained that I hated being wakened in the middle of the night and that I wanted to be home in my own bed. I didn't want to be in this stupid hospital. She said, "Now you have to get up and pee." I said, "I'm not going to, and I'm not going to take my medicine either!" Katy looked very grim and said, "You can't say that." I said, "I don't care! I hate this hospital!" She hit be on the shoulder, looking very stern. I said, "Why am I in this hospital?" She said, "You have cancer." I said, "I hate cancer and I hate chemotherapy, because it makes me feel so awful. I'm not having any more chemotherapy or radiation!" She said, "You have to have surgery." I said, "No!" She hit me again and said, "You already had your surgery." I said, "Yes, and it hurt so much after I woke up." She said, "Now you're going get a broviac." I said, "What's a broviac?" She said, "It's just a little tube that goes into your chest." I said, "I'm not getting any broviac!" She hit me again and said, "Yes you are, and you're going to get an i.v. and a shot too." I made several comments at the end of this hour, that she had helped me know how it felt to be in the hospital and shown me many of the things that she hadn't liked, that she had helped me feel how scary it could be for a kid, how mad a kid could get about having all kinds of hurting and scary things done to her, how a kid hated to be forced and how confusing it felt when doctors, who were supposed to be helping, sometimes did things that hurt a kid.

In the sessions immediately following, Katy began to take the role of the patient. For example, she took the cushions off my office chairs and lay down on them. She instructed me to get some puppets who should wake her up. The puppets told her it was time to wake up and she woke up with a vengeful look and began pummeling the puppets until they were knocked off my hands and flung across the room. When I had the puppets say, "Wake up, it's time to take your temperature and go to the bathroom," Katy bit the puppets and threw them against the wall. She represented the pain she experienced in the hospital using the doll figures and blocks. She made a bed out of blocks and put a girl figure on the bed. Then she built up the sides of the bed and placed other figures there, standing over the girl. I commented that the girl looked like she was in the hospital and Katy confirmed this. Then the figures standing over the girl pushed blocks on top of her. I said, "I think you're remembering about doctors and nurses looking down at you. What happened to the girl showed me how confusing it could be to have doctors hurt you when they were supposed to be taking care of you." 
Over the next several sessions, Katy's play shifted from hospital themes to themes of protection and safety. She crawled under a chair and refused to talk to me. She brought her hand out from under the chair and motioned that I was to chase it with my hand. My hand chased hers, but was never able to catch it. Then she began grabbing my intruding hand and throwing it out from under the chair, and looked very pleased with her ability to repulse me. I commented that it looked like she was in a very safe spot under the chair, and that it must feel good to be in a safe spot. She probably felt in the hospital that there weren't any safe spots. She couldn't get away from having people do things that scared her and hurt her and she must have wished then for a safe spot. I said, "In our game, you're the one in control. When my hand comes in, yours is too fast and always gets away. Or else your hand is too strong, and throws mine out. I bet you wished that you could have thrown those doctors and nurses away from your bed in the hospital." She elaborated this safety game by pretending to be a kitty who was in her special safe spot. I said, "Neither kitties or girls like it when people touch them and they don't want to be touched. Especially when the kitty has to go to the vet, she wants to run away to a safe spot."

By now the treatment was in its third month and Katy's parents were reporting that she was becoming much more social at school, that she seemed less inhibited and that, in particular, she was expressing negative or angry feelings much more openly. She was becoming very bossy to her brother and had some angry outbursts toward her mother. Her mother had been taken aback, because this was so unlike Katy. Her parents were pleased, however, because Katy was expressing a wider range of feelings.

The last month and one half of treatment focused on themes of mastery and putting her illness in perspective. I have selected three hours during this final phase which seemed not only to summarize the issues of the treatment, but also underscore the strong progressive developmental forces in Katy, which were becoming more available to her.

In the first of these hours, Katy pushed a chair over to the window, got up on it and looked out at a nearby park. She pointed out a play ground. Then she began jumping off the chair. At first she held my hand each time, then began jumping off on her own. I said, "This reminds me of how you used to be afraid of jumping or falling, because you had the mix-up that falling off the jungle gym made you get cancer. Now I can see that you can jump without being too scared." Katy did not respond verbally, but went into the closet and pulled the door shut. She pretended to be a kitten locked in the closet and it was my job to let her out. Several times when I opened the door, she had a very somber expression and I commented that the kitty was looking sad. About the fifth time I opened the door, she had a very happy expression and pranced around the room, flapping her arms, pretending to fly. This scenario was repeated about four times. Then, when I opened the door, her expression was threatening and she poked at me with a coat hanger. Next she huddled up in the corner, hiding her head. Finally, the flying girl came out again. I commented that her happy play reminded me about how she felt before she got cancer. But then she got sick and felt awful and scared and sad and just wanted to huddle up and hide from people who might hurt her. Sometimes she was also very angry, but was afraid to let people know she was mad. I 
said, "Now that you're feeling much better, it seems like you can be a happy, flying girl again, who can do lots of things. Maybe you're not so worried now about getting sick again."

A few days before the second significant hour in the final phase Katy had had her six months CAT scan and it had been normal. Katy spent much of the hour showing me tricks she could do. She jumped off the chair in a number of different ways-first off the seat, then higher from the arm, then backwards off the seat. She did somersaults and pretended to be a ballet dancer. I admired all the things she could do and complimented her abilities and her initiative. She also spent a good deal of time carefully building a house out of Lincoln Logs. I was pleased to see this kind of play because it is a normal type of skill-building play for a five year old. A shift from play referring to trauma to such developmentally appropriate and conflict-free play is one of the signs that a child is becoming free from the preoccupation with traumabased anxiety.

At the beginning of the third significant hour, which occurred a few sessions before treatment was concluded, I began by saying, "Your mom told me that your CAT scan showed you don't have any more cancer." Katy said, "Yes" and immediately became the kitty. She had me pull the two office chairs together to make a bed. The kitty climbed on to the bed, yawned, stretched luxuriously and went to sleep. She smiled in her sleep, and I commented that the kitty looked like she was having nice dreams. Then the kitty climbed down and frolicked around on the floor. I said, "The kitty looks like she's feeling very good. I bet she's happy now because she doesn't have to go to the vet all the time or stay in the kitty hospital." The kitty answered by rolling around on the floor, stretching and going to sleep. Then kitty woke up, looked very alert and began bringing me things in her teeth: a plastic dinosaur, a little plastic table, a piece of string. I said, "The kitty's very good at picking things up with her teeth." Then I decided to reintroduce the medical theme into the play saying, "I don't know if you can carry that big doctor's kit in your teeth-it might be too heavy." Katy grinned at this challenge and picked it up in her teeth and carried it over to me. Then she opened the kit and immediately took on an angry expression. She dumped everything out and scattered it across the floor. I said, "The kitty doesn't like all that doctor's stuff. Maybe it reminds her of the vets and the kitty hospital. She took a surgeon's cap and mask and stuffed them in a drawer and slammed it shut. I said, "The kitty hates all that doctor's stuff. She doesn't even want to see it." Then she initiated a game of chasing a ball and bringing it back to me. Once while chasing the ball, she came across the doctor's kit and flung it across the room. I said, "The kitty doesn't like that doctor stuff because it reminds her of when she was in the hospital and people did things that hurt her. But it's very good that the kitty is healthy now because it means she won't have to stay in the hospital. She'll have to go to the doctor for checkups and tests, but that won't be like staying in the hospital." Katy handed me a toy syringe and motioned for me to give her a shot. I did and said, "That shot was to keep you from getting sick. It didn't seem to hurt too much." She handed me the stethoscope and I listened to her heart and said, "It sounds very good." The kitty yawned and stretched contentedly. I summarized this play by saying, "I know that you're just like the kitty, you're very happy to be feeling good again." 
During the remaining few hours before termination, the medical themes were absent from Katy's play. However, more generalized issues of anxiety about being hurt and feeling safe were brought up, particularly in response to the pressure of termination. For example, Katy spent a lot of time standing on the arm of the chair looking out the window and she wanted me to be close to her. She repeatedly pretended to lose her balance and had to grab on to me to keep from falling. I interpreted this in two ways, saying, "This reminds me how you used to be afraid of falling because you thought that had caused your cancer. But that's not true. Falling down didn't cause it." I also said, "Since you've been seeing me, you've been feeling lots better, lots happier and you can do more fun things, like play games with other kids and even climb to the top of the jungle gym. Maybe you're worried that when you stop seeing me, you'll start falling again. But that's not going to happen because you've been practicing and you've gotten very good at climbing and jumping and at keeping yourself safe. And now you don't need to get extra worried about falls and bumps because you know that even though they might hurt they're not going to make you sick."

At the end of this five month long therapy Katy was far more expressive, showed a fuller range of affects, was much less anxious about her physical safety, was more active physically and was more social. Treatment helped her give up her internal preoccupation with and anxiety about her medical experiences. There are other factors besides therapy which contributed to her resumption of an apparently normal developmental trajectory. These included her relief that she was feeling better physically, her opportunity in the day care center to become a "regular kid" interacting with other kids, and her parents' ability to support her assertiveness and expressiveness.

\section{Follow-Up}

There have been several opportunities for follow-up after termination of psychotherapy, including some brief visits with Katy and telephone contact with her parents. Medically, Katy continues to do well. Her CAT scans remain normal 2 years after cancer treatment ended. On follow-up visits with me, Katy presented as a calm, articulate, playful child with a mischievous sense of humor. She remains physically active and has a number of friends at school. At the same time, residues of her experience with cancer can be seen in a prevailing watchfulness and seriousness uncharacteristic for her age. Her parents also provided information which made me realize that $I$ had not sufficiently addressed her fears about dying. For Halloween, she had insisted on dressing up as an angel. I reflected that this was probably the more specific fantasy underlying the happy girl who flew around my office. Although I had watched for themes of death, I suspect that my resistance to considering Katy's death prevented me from understanding her angel play. Nevertheless, I do not regret my interpretation of this play as representing Katy's precancer happy self, because it emphasized Katy's capacity for vibrancy and happiness in this life. It is not clear yet whether learning disabilities associated with cranial irradiation are present. If she does have learning problems, it seems likely that Katy may be able to compensate for them, since she is a bright and resilient child who has parents who will seek special help for her if needed. 


\section{Discussion}

Psychotherapy enabled Katy to represent in play her subjective account of cancer treatment. Her play presented a story of a young child who felt frightened, helpless and rageful, was confused by the pain of treatment that was supposed to help, and viewed herself as a victim of sadism, and perhaps as deserving punishment for being bad. This affectively-rich play representation was very different from her selfpresentation while hospitalized, when, for the most part, she was subdued, compliant and cooperative. Out of necessity, Katy had developed the ability to modulate and contain anxious reactions to all but the most painful or frightening procedures. Her precocious defenses and her ability to accept the support of her empathic and competent parents made it appear that she was coping well with her difficult medical treatment. However, as the story of her play suggests, it is important to distinguish between immediate coping and actual mastery. Katy's play in therapy suggested that her coping capacity represented a self-protective process developed in a series of psychic emergencies, not psychological mastery of the experiences. After her medical treatment ended, the need to understand, master and integrate her experience with cancer still remained. Paradoxically, her defenses had become organized around the need to suppress activity and affect; consequently, the normal means a preschooler uses to master and understand experience-play and fantasy-had become inhibited and were less available to Katy as vehicles for mastery. For this reason, restoring the ability to play became an essential goal of the early stage of therapy.

Katy's continuing reliance on the emergency-based defenses was having more pervasive effects on her development because she tended to overgeneralize them to non-emergency situations. The inhibitive strategies she developed during hospitalizations-compliance, overcontrol of affects, emotional withdrawal-became maladaptive when applied to normal tasks of preschool development such as entering into peer relations and developing the capacity for initiative through imagination and physical activity. As she was able to represent the story of her cancer treatment and have it confirmed and then interpretively differentiated from her current experience by a therapist to whom she had become attached, Katy was gradually able to gain a significant degree of mastery over a series of extremely stressful experiences. It is possible to track the development of mastery by abstracting the main trends of therapy. At first Katy was inhibited in 
affect, fantasy and activity level. After the therapist indicated interest in her hospital experiences and encouraged the expression of affect, Katy progressively found ways to represent the negative feelings associated with cancer treatment. In the hospital play, Katy first attempted mastery through role reversal, putting the therapist in the position of the hurt, frightened, angry child. This gave the therapist the opportunity to put Katy's unspoken story into words and to empathize with what she had been through. The therapist helped Katy conceptualize her experience and differentiate it from present reality. An important shift occurred when Katy gave up the medical play and established her "safe spot" under the chair. By controlling and repelling the therapist's play intrusions into her "safe spot," Katy was mastering the repeated intrusions during her hospitalizations. The therapist emphasized her ability to gain control. During the last phase of treatment two themes coexisted. One was oriented to the present and involved testing her physical abilities by jumping off the chair and doing somersaults. The therapist acknowledged her physical competence, and used Katy's physical activity as an opportunity to contradict her earlier belief that physical daring had been the cause of her cancer. Occurring in the context of therapy, Katy's physical activity represented her struggle to master fears of body damage. (During this period, her parents reported that she had resumed climbing on the jungle gym and was swinging again.) The second theme was play that "summarized" her experience with cancer and placed it in the context of her life. This was expressed through the kitty character who seemed to go through cycles of intense anxiety and anger followed by relief and contentment. The therapist interpreted this play to help her construct a view of her illness as a painful and frightening past experience that she would remember but was separate from her current life.

It is likely that individual psychotherapy for childhood cancer survivors is de-emphasized by some writers (Chesler and Barbarin, 1987) because it is associated with the treatment of psychopathology. Chesler and Barbarin point out that children's responses to cancer treatment should be seen as normal reactions to abnormal stressors. One can fully agree with this de-pathologizing perspective and at the same time assert that normal coping mechanisms in response to severe stress may evolve into maladaptive defenses which interfere with normal development in the young child. Play therapy focused on the child's reactions to cancer treatment can offer the child a chance to share his or her story of having cancer in all its affective complexity and to master developmental impasses related to it. 


\section{Acknowledgments}

Portions of this paper were presented in an institute, "Uses of Play Therapy: Concepts and Techniques," at the 68th Annual Meeting of The American Orthopsychiatric Association, Toronto, March 24, 1991.

I am indebted to John Bennett, Jr., M.S.W., Irving Leon, Ph.D. and Jonathan Sugar, M.D. for their helpful comments during the preparation of this paper.

\section{References}

Adams-Greenly, M. (1989) Psychosocial Interventions in Childhood Cancer. In J. C. Holland and J. H. Rowland, eds. Handbook of Psychooncology. New York and Oxford: Oxford University Press.

Barton, M. L. and Zeanah, C. H. (1990). Stress in the Preschool Years. In L. E. Arnold, ed. Childhood Stress. New York: John Wiley.

Bergmann, T. and Freud, A. (1965). Children in the Hospital. New York: International Universities Press.

Bibace, R. and Walsh, M. E. (1980). Development of Children's Concepts of Illness. Pediatrics, 66, 912-917.

Blount, R. L., Davis, N., Powers, S. W., and Roberts, M. C. (1991). The Influence of Environmental Factors and Coping Style on Children's Coping and Distress. Clinical Psychology Review, 2, 193-216.

Brunnquell, D. and Hall, M. D. (1982). Issues in the Psychological Care of Pediatric Oncology Patients. American J. Orthopsychiatry, 52, 32-44.

Chang, P. (1990). Psychosocial Needs of Long-term Cancer Survivors: A Review of the Literature. Pediatrician, 18 (1), 20-24.

Chesler, M. A. and Barbarin, O. A. (1987). Childhood Cancer and the Family. New York: Brunner/Mazel.

Chethik, M. (1989). Techniques of Child Therapy: Psychodynamic Strategies. New York: Guilford Press.

Ciccetti, D., Cummings, E. M., Greenberg, M. T., and Marvin, R. S. (1990). An Organizational Perspective on Attachment Beyond Infancy: Implications for Theory, Measurement and Research. In M. T. Greenberg, D. Cicchetti and E. M. Cummings, Attachment in the Preschool Years. Chicago: University of Chicago Press.

Deasy-Spinetta, P. (1981). The School and the Child With Cancer. In J. J. Spinetta, and P. Deasy-Spinetta, eds. Living with Childhood Cancer. Springfield, IL: Charles C. Thomas.

Fritz, G. K., Williams, J. R., and Amylon, M. (1988). After Treatment Ends: Psychosocial Sequelae in Pediatric Cancer Survivors. American $J$. of Orthopsychiatry, 58, $552-561$.

Gauvain-Piquard, A., Rodary, C. Rezvani, A. and Lemerle, J. (1987). Pain in Children Aged 2.6 Years: A New Observational Rating Scale Elaborated in a Pediatric Oncology Unit: Preliminary Report. Pain. 31 (2), 177-188.

Greenberg, H. S., Kazak, A. E., and Meadows, A. T. (1989). Psychologic Functioning in 8-to 16-year-old Cancer Survivors and Their Parents. J. Pediatrics, 114, 488-93.

Jay, S. M., Ozolins, M., Elliot, C. H., and Caldwell, S. (1983). Assessment of Children's Distress During Painful Medical Procedures. Health Psychology, 2, 133-47.

Jay, S. M. (1988). Invasive Medical Procedures: Psychological Intervention and Assessment, in D. K. Routh, ed. Handbook of Pediatric Psychology. New York: Guilford Press. 
Kagan, J. (1983). Stress and Coping in Early Development. In N. Garmezy and M. Rutter, eds. Stress, Coping and Development in Children. New York: McGraw-Hill.

Kagen-Goodheart, L. (1977). Reentry: Living With Childhood Cancer. American J. Orthopsychiatry, 47, 651-659.

Katz, E. R. (1980). Illness Impact and Reintegration. In J. Kellerman, Psychological Aspects of Childhood Cancer. Springfield, IL: Charles C. Thomas.

Koocher, G. P., O'Malley, J.E., Gogan, J. L., and Foster, D. (1980). Psychological Adjustment Among Pediatric Cancer Survivors. J. Child Psychology and Psychiatry, $21,163-173$.

Lansky, L. L., List, M. A., Lansky, S. B., Cohen, M. E. and Sinks, L. F. (1985). Toward the Development of a Play Performance Scale for Children (PPSC). Cancer, 56, 1837-1840.

Lansky, S. B., Zwartges, W. and Cairns, N. U. (1983) School Attendance Among Children With Cancer. J. Psychosocial Oncology. 2, 75-82.

Maccoby, E. E. (1983). Social-Emotional Development and Response to Stressors. In N. Garmezy and M. Rutter, eds. Stress, Coping and Development in Children. New York: McGraw-Hill.

Mulhern, R. K., Wasserman, A. L., Friedman, A. G., and Fairclough, D. (1989). Social Competence and Behavioral Adjustment of Children Who Are Long-Term Survivors of Cancer. Pediatrics, 83, 18-25.

Piaget, J. (1962). Play, Dreams and Imitation in Childhood. New York: Norton.

Rowland, J. H. (1989). Developmental Stage and Adaptation: Child and Adolescent Model, in J. C. Holland and J. H. Rowland, eds. Handbook of Psychooncology. New York and Oxford: Oxford University Press.

Rutter, M. (1983). Stress, Coping and Development: Some Issues and Some Questions. In N. Garmezy and M. Rutter, eds. Stress, Coping and Development in Children. New York: McGraw-Hill.

Siegel, K. (1990). Psychosocial Oncology Research. Social Work in Health Care, 15 (1), 21-43.

Susman, E. J. Hollenbeck, A. R., Nannis, E. D., and Strope, B. E. (1980). A Developmental Perspective on Psychosocial Aspects of Childhood Cancer. In J. L. Schulman and M. J. Kupst, eds. The Child With Cancer. Springfield, IL: Charles C. Thomas.

Trad, P. V. and Greenblatt, E. (1990). Psychological Aspects of Child Stress: Development and the Spectrum of Coping Responses. In L. E. Arnold, Childhood Stress. New York: John Wiley.

Van Dongen-Melman, J. E. W. M. and Sanders-Woudstra, J. A. R. (1986). Psychosocial Aspects of Childhood Cancer: A Review of the Literature. J. Child Psychology and Psychiatry. 27, 145-180.

Wells, K. (1987). Scientific Issues in the Conduct of Case Studies. J. Child Psychology and Psychiatry, 28, 783-90.

Zeltzer, L. K. and LeBaron, S. (1986). Fantasy in Children and Adolescents With Chronic Illness. Developmental and Behavioral Pediatrics. 7, 195-198. 